\title{
QUALITY OF LIFE OF PATIENTS WITH GLAUCOMA
}

\author{
Binna Nenkova, Maya Pandova \\ Department of ophthalmology and visual sciences, Medical University of Varna
}

\begin{abstract}
INTRODUCTION: Visual impairments are a serious problem due to the limitations that they impose in everyday life and the loss of independence.

AIM OF THE STUDY: To analyze the way the demographic variables (gender, age, place of residence, education, marital status and employment status) affect the quality of life; the way the quality of life changes and which activities are affected by the impairment of the visual functions.

MATERIAL AND ETHODS: 54 individuals with proven glaucoma and permanent low vision have been surveyed (assessment criteria of the impairment degree is the correction of the better eye). With a view to do this we used LWQOL Wolffson J S 2000. The questionnaire contains four chapters: demographic, general diseases, ophthalmological status and psychometric section including four dimensions (Distance, mobility and illumination vision; Adaptation; Reading and fine work and Everyday activities). We have determined the reliability of the questionnaire with the help of the Cronbach`s alpha coefficient.

RESULTS: The average quality of life score is $81,5 \pm 17,4$. The quality of life impairs with ageing $(94,5 \pm 13.6$ for individuals above 80 years of age). Although the difference in terms of place of residence is insignificant, the worst quality of life is shown by the village residents $(82,8 \pm 13,1)$. For the married individuals a higher quality of life is observed contrary to those who live alone. The lowest quality of life is observed for the individuals who live with their children $(87,8 \pm 19,7)$. The low educational degree correlates with a low quality of life. Regarding the employment status the worst indicators are observed for the retired individuals followed by those who have retired due to an illness. The most affected activities are those related to illumination, mobility and fine work.

CONCLUSIONS: The quality of life impairment for glaucoma patients is directly associated to the demographic indicators and the visual impairment degree. The low percentage of usage of auxiliary means $(7,40 \%)$ by the questioned patients shows low motivation and insufficient level of information.
\end{abstract}

Keywords: quality of life, demographic variables, visual functions, glaucoma, disability

Address for correspondence:

Binna Nenkova

Department of ophthalmology and visual sciences,

Medical University of Varna

55 Marin Drinov Str.

9002 Varna, Bulgaria

e-mail: bnenkova@gmail.com

Received: Juje 27, 2015

Accepted: December 01, 2015

\section{INTRODUCTION}

Ageing of population and increasing number of individuals with visual impairment - those that can not be helped with the traditional optical, medication and surgical methods - is a challenge for ophthalmologists. Visual impairments are a serious problem due to the limitations they pose in patient's everyday life and due to the lack of independence. 
Quality of life is an indicator evaluating the results of social policy in the healthcare and social fields. Thus it is important to assess how the quality of life changes for individuals with visual impairment.

Regardless of the introduction of new medications and surgical techniques for glaucoma treatment, this disease remains the leading cause for blindness worldwide. In 2010 the number of individuals suffering from glaucoma was 60.5 million and it is estimated that in 2020 the number will be 79.6 million, 11.2 million of which will be with binocular blindness. Quigly HA, 2010 (15).

The Quality of life assessment is performed with special tools - questionnaires, which provide information on the evaluation of activities related to everyday life from the patient's point of view.

Objective: quality of life analysis for patients with glaucoma; determining the relationship between the demographic variables, the influence of visual impairment degree, duration of the disease and its reflection on different everyday activities.

\section{MATERIAL AND METHODS:}

The used questionnaire is LVQOL Wolfsson 2000 (22) created for individuals with impaired vision regardless of their illness. The questionnaire includes four sections - demographic (gender, age, residence, education, marital status, employment), accompanying diseases, ophthalmic status (corrected vision, tonometry, duration of disease and applied treatment) and a psychometric section which has four dimensions (Distance, mobility and illumination vision; Adaptation; Reading and fine work and Everyday activities).

We have determined the reliability of the questionnaire with the help of the Cronbach 's alpha coefficient, and our results have shown a very good value of the coefficient $(0,96)$. The evaluation of the status of the different activities was performed according to the Likert scale 0 - 5 , where 0 stands for lack of difficulties, and 5 stands for impossibility to perform a certain activity due to visual impairment. All participants have filled out an informed consent declaration. The questioned individuals were divided into three groups depending on the severity of the visual impairment: 0.05, 0.06-0.09, 0.1-0.3. Every patient has a proven diagnose and permanently impaired vision.

\section{RESULTS}

54 individuals were questioned $-64,80 \%$ men and $35,20 \%$ women. The average age of the questioned individuals is 68,85 years $\pm 11,02$ years, the minimum age being 32 years, and the maximum being 86 years.tabl. 1 .

The average quality of life score is $81,5 \pm 17,4$. Approximately half of the patients are above the average quality of life level 81,5 (53,70\%) (fig. 1).

The age group distribution has shown that the number of patients is biggest in the age group 60-79 years $(59,30 \%)$. According to the residence the individuals living in the district city prevail $29(53,70 \%)$, followed by those from the villages 14 (25,90\%).

The educational structure shows that significant part of the studied individuals have low education degree 23 (42,60\%), who have stopped their education at primary level and just $38,90 \%$ have secondary education.

More than the half of the questioned individuals are married $35(64,8 \%)$, followed by the widowed patients $14(25,90 \%)$.

The analysis of the employment shows that 37 $(68,50 \%)$ are retired due to age, and 13 are retired due to illness $(24,10 \%)$.

From the accompanying diseases the cardiovascular conditions have the biggest percentage $80,00 \%$ - heart attack - 64,70\% ischemic heart disease (tabl. $3)$.

Reviewing of the different quality of life dimensions has shown a significant difference in terms of the weight of the impairment and the degree of affecting different activities excluding the explanation of the eye disease. On this indicator all three groups presented an approximately equal value which shows that the studied individuals determine the status of their eyes as poor (table 4).

According to the impairment degree, a certain difference $(p<0,05)$ is present in the general QoL - the worst indicator is present for the individuals with vision e $0.05(4,35 \pm 1,31)$, regarding the second dimension - angry $(2,84 \pm 1,61)$ and unhappy $(4,67 \pm 0,65)$ and regarding the third dimension within the subscale - using tools $(4,81 \pm 0,40)$.

The assessment data for mobility and fine work show bad indicators - 3,48 $\pm 0,72$. We have also found a significant dependence between the general quality 


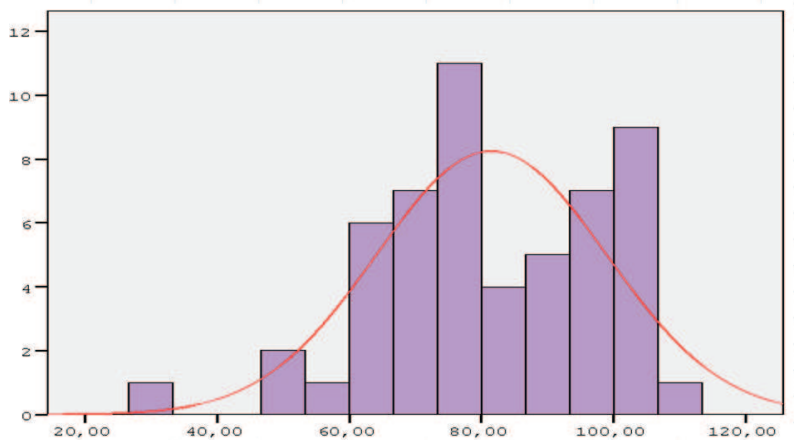

Fig. 1. Distribution of patients with glaucoma according to their general quality of life score

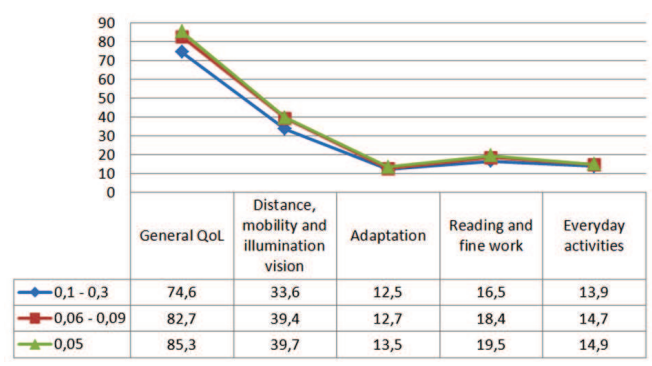

Fig. 2. Ratio of visually impaired individuals with glaucoma according to the impairment type and their quality of life

Table 1. Social and demographical characteristics

\begin{tabular}{|c|c|c|c|}
\hline \multirow{2}{*}{ Indicator } & & \multicolumn{2}{|c|}{ Distribution } \\
\hline & & \multirow{2}{*}{$\begin{array}{c}\text { Number } \\
35\end{array}$} & \multirow{2}{*}{$\begin{array}{c}\text { Relative share } \\
64,80 \%\end{array}$} \\
\hline \multirow{2}{*}{ Gender } & Men & & \\
\hline & Women & 19 & $35,20 \%$ \\
\hline \multirow{6}{*}{ Age } & Average age $( \pm \mathrm{SD})$ & \multicolumn{2}{|c|}{68,85 years $\pm 11,02$ years } \\
\hline & $0-19$ years & - & - \\
\hline & $20-39$ years & 1 & $1,90 \%$ \\
\hline & $40-59$ years & 11 & $20,40 \%$ \\
\hline & $60-79$ years & 32 & $59,30 \%$ \\
\hline & Above 80 years & 10 & $18,50 \%$ \\
\hline \multirow{3}{*}{ Residence } & District city & 29 & $53,70 \%$ \\
\hline & Other city & 11 & $20,40 \%$ \\
\hline & Village & 14 & $25,90 \%$ \\
\hline \multirow{6}{*}{ Education } & Uneducated & - & - \\
\hline & Elementary & 6 & $11,10 \%$ \\
\hline & Primary & 23 & $42,60 \%$ \\
\hline & Secondary & 21 & $38,90 \%$ \\
\hline & College & - & - \\
\hline & University & 4 & $7,40 \%$ \\
\hline \multirow{4}{*}{ Marital status } & Married & 35 & $64,80 \%$ \\
\hline & Divorced & 4 & $7,40 \%$ \\
\hline & Widowed & 14 & $25,90 \%$ \\
\hline & Single & 1 & $1,90 \%$ \\
\hline \multirow{3}{*}{ Living } & With spouse & 35 & $64,80 \%$ \\
\hline & Alone & 10 & $18,50 \%$ \\
\hline & With their children & 9 & $16,70 \%$ \\
\hline \multirow{3}{*}{ Employment } & Retired due to illness who doesn't work & 13 & $24,10 \%$ \\
\hline & Retired due to age & 37 & $68,50 \%$ \\
\hline & Working & 4 & $7,40 \%$ \\
\hline
\end{tabular}

Scripta Scientifica Salutis Publicae, vol. 1, No. 2, 2015, pp. 33-41 
of life and its dimensions and the impairment type. (fig. 2 and table 5).
The results of our study confirmed the literature data that the disease type is not one of the leading factors for determining the quality of life level,

Table 2. Quality of life assessment for patients with low vision

\begin{tabular}{|c|c|c|c|c|c|c|}
\hline \multirow{2}{*}{ INDICATOR } & & \multicolumn{5}{|c|}{ QUALITY OF LIFE } \\
\hline & & 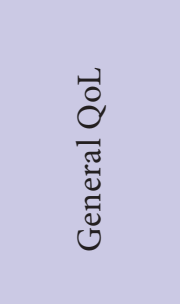 & 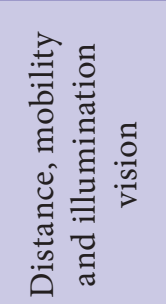 & 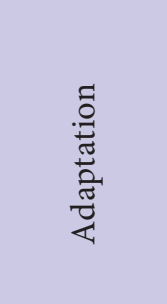 & 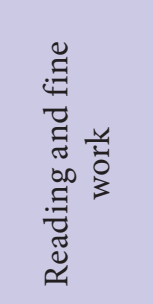 & $\begin{array}{l}\text { Everyday } \\
\text { activities }\end{array}$ \\
\hline \multirow{2}{*}{ Gender } & Men & $84,4 \pm 15,7$ & $38,8 \pm 7,8$ & $12,9 \pm 2,7$ & $19,4 \pm 4,3$ & $15,7 \pm 3,6$ \\
\hline & Women & $76,2 \pm 19,5$ & $36,1 \pm 9,0$ & $12,9 \pm 3,8$ & $16,6 \pm 5,1$ & $12,3 \pm 5,0$ \\
\hline \multirow{5}{*}{ Age } & $0-19$ years & - & - & - & - & - \\
\hline & $20-39$ years & - & - & - & - & - \\
\hline & $40-59$ years & $73,3 \pm 14,3$ & $34,5 \pm 7,5$ & $11,6 \pm 3,8$ & $16,5 \pm 3,4$ & $12,7 \pm 3,3$ \\
\hline & $60-79$ years & $80,6 \pm 17,7$ & $37,4 \pm 8,5$ & $12,9 \pm 3,1$ & $18,1 \pm 4,7$ & $14,2 \pm 4,7$ \\
\hline & Above 80 years & $94,5 \pm 13,6$ & $43,9 \pm 5,6$ & $13,9 \pm 1,8$ & $22,0 \pm 4,7$ & $17,8 \pm 3,3$ \\
\hline \multirow{3}{*}{ Residence } & District city & $81,1 \pm 18,2$ & $37,4 \pm 8,6$ & $12,2 \pm 3,3$ & $18,5 \pm 4,6$ & $15,1 \pm 4,3$ \\
\hline & Other city & $80,9 \pm 21,0$ & $37,3 \pm 9,4$ & $14,5 \pm 2,0$ & $17,7 \pm 6,1$ & $13,4 \pm 5,6$ \\
\hline & Village & $82,8 \pm 13,1$ & $39,1 \pm 7,1$ & $13,1 \pm 2,9$ & $18,6 \pm 4,1$ & $14,4 \pm 3,9$ \\
\hline \multirow{6}{*}{ Education } & Uneducated & - & - & - & - & - \\
\hline & Elementary & $94,0 \pm 12,3$ & $43,2 \pm 7,7$ & $14,5 \pm 4,3$ & $21,8 \pm 4,3$ & $17,5 \pm 3,3$ \\
\hline & Primary & $85,0 \pm 15,5$ & $39,4 \pm 6,8$ & $14,2 \pm 2,4$ & $19,0 \pm 4,3$ & $14,7 \pm 4,5$ \\
\hline & Secondary & $75,6 \pm 18,9$ & $35,5 \pm 9,3$ & $11,3 \pm 2,8$ & $17,0 \pm 5,1$ & $13,4 \pm 4,6$ \\
\hline & College & - & - & - & - & - \\
\hline & University & $73,7 \pm 14,6$ & $33,3 \pm 8,1$ & $11,5 \pm 2,1$ & $16,7 \pm 4,9$ & $14,5 \pm 3,3$ \\
\hline \multirow{4}{*}{ Marital status } & Married & $79,6 \pm 18,2$ & $36,5 \pm 8,5$ & $12,8 \pm 3,2$ & $18,1 \pm 5,1$ & $14,1 \pm 4,9$ \\
\hline & Divorced & $73,0 \pm 17,0$ & $35,0 \pm 10,5$ & $11,3 \pm 2,8$ & $16,3 \pm 2,9$ & $13,0 \pm 2,0$ \\
\hline & Widowed & $89,8 \pm 13,2$ & $42,5 \pm 6,1$ & $14,1 \pm 2,3$ & $19,8 \pm 4,3$ & $16,1 \pm 3,5$ \\
\hline & Single & - & - & - & - & - \\
\hline \multirow{3}{*}{ Living } & With spouse & $76,9 \pm 18,2$ & $36,5 \pm 8,5$ & $12,8 \pm 3,2$ & $18,1 \pm 5,1$ & $14,1 \pm 4,9$ \\
\hline & Alone & $82,4 \pm 11,5$ & $39,7 \pm 5,3$ & $13,4 \pm 3,1$ & $17,9 \pm 3,1$ & $14,0 \pm 2,7$ \\
\hline & With their children & $87,8 \pm 19,7$ & $41,2 \pm 9,8$ & $12,6 \pm 3,2$ & $20,0 \pm 5,1$ & $16,6 \pm 3,7$ \\
\hline \multirow{3}{*}{ Employment } & $\begin{array}{l}\text { Retired due to illness who } \\
\text { doesn't work }\end{array}$ & $81,9 \pm 14,3$ & $37,3 \pm 6,8$ & $14,1 \pm 3,1$ & $18,1 \pm 3,9$ & $14,6 \pm 3,9$ \\
\hline & Retired due to age & $83,0 \pm 18,3$ & $38,7 \pm 8,7$ & $12,9 \pm 2,8$ & $18,8 \pm 5,2$ & $14,7 \pm 4,7$ \\
\hline & Working & $66,0 \pm 12,3$ & $31,5 \pm 7,8$ & $9,3 \pm 3,2$ & $15,3 \pm 2,2$ & $12,0 \pm 0,0$ \\
\hline
\end{tabular}


Table 3. Type of impairment and accompanying diseases

\begin{tabular}{l|c|c|c|}
\hline & \multicolumn{3}{|c|}{ Type of visual impairment } \\
\cline { 2 - 4 } Disease & $0,1-0,3$ & $0,06-0,09$ & 0,05 \\
\hline
\end{tabular}

Hypertensive disease (HD)

$N=39$

$10 / 25,60 \% \quad 6 / 15,40 \% \quad 23 / 59,00 \%$

Diabetes

$\mathrm{N}=15$

$4 / 26,70 \%$

$2 / 13,30 \%$

$9 / 60,00 \%$

Ischemic heart disease (IHD)

$N=17$

$5 / 29,40 \% \quad 1 / 5,90 \% \quad 11 / 64,70 \%$

Heart attack

$N=5$

$1 / 20,00 \%$

$-$

$4 / 80,00 \%$

Stroke

$N=7$

$2 / 28,60 \%$

$1 / 14,30 \%$

4/ $57,10 \%$

Cranial - brain tumors

$N=4$

$1 / 25,00 \%$

$1 / 25,00 \%$

$2 / 50,00 \%$

Thrombophlebitis

$N=14$

$3 / 21,40 \%$

$3 / 21,40 \%$

$8 / 57,10 \%$

Malignant neoplasm

$\mathrm{N}=12$

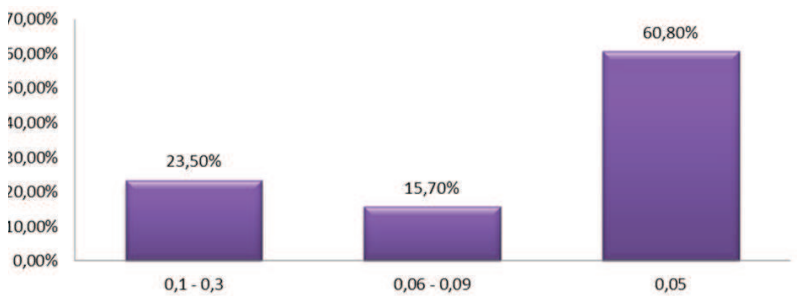

Fig. 3. Distribution of patients according to the impairment degree

but what plays a significant role is the visual impairment degree and type (central or peripheral). The results are presented in table 6 .

The data in table 6 shows that despite the lack of a significant difference in the quality of life indicators, the worst scores belong to the individuals with refractive anomalies and diseases.

Despite the high percentage of patients with 0,05 vision, those that use aiding tools are barely $7,40 \%$ ( 4 of 54). The probable reason for this is low motivation and lack of information.

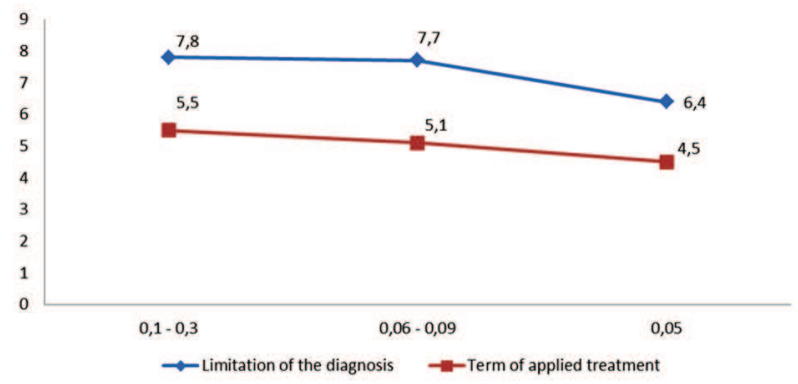

Fig. 4. Limitation and term of the diagnosis and applied treatment

When analyzing the impairment type in accordance with the social and demographic factors we haven't found significant differences in the distribution of the questioned individuals which can be explained with the prevailing percentages of the separate variations of the reviewed indicators.

Despite of not observing any significant difference in terms of the limitation and the term of the diagnosis and the quality of life, we can conclude that for most patients there is an approximately two year period between setting the diagnosis and starting the treatment (fig. 4). 
Table 4. Average assessment of the QoL dimensions depending on the impairment type

\begin{tabular}{|c|c|c|c|c|c|}
\hline & \multicolumn{5}{|c|}{$\begin{array}{l}\text { Average assessment of the QoL dimensions depending on the impairment } \\
\text { type }\end{array}$} \\
\hline & Total & $0,1-0,3$ & $0,06-0,09$ & 0,05 & $\mathrm{P}$ \\
\hline \multicolumn{6}{|c|}{ Distance, mobility and illumination vision } \\
\hline 1. General vision & $4,09 \pm 1,46$ & $3,16 \pm 1,58$ & $4,50 \pm 1,41$ & $4,35 \pm 1,31$ & $<0,05$ \\
\hline 2. Eyes getting tired & $2,32 \pm 1,14$ & $1,92 \pm 0,79$ & $2,50 \pm 0,53$ & $2,42 \pm 1,33$ & $>0,05$ \\
\hline 3. Night vision & $3,06 \pm 0,54$ & $2,83 \pm 0,39$ & $3,25 \pm 0,46$ & $3,09 \pm 0,59$ & $>0,05$ \\
\hline 4. Getting right amount of light & $3,09 \pm 0,83$ & $2,83 \pm 0,39$ & $3,50 \pm 0,92$ & $3,09 \pm 0,91$ & $>0,05$ \\
\hline 5. Glare (dazzled by lights) & $3,33 \pm 1,16$ & $3,00 \pm 1,04$ & $3,50 \pm 0,93$ & $3,41 \pm 1,26$ & $>0,05$ \\
\hline 6. Ability to see street signs & $3,25 \pm 0,77$ & $2,83 \pm 0,83$ & $3,25 \pm 0,46$ & $3,42 \pm 0,76$ & $>0,05$ \\
\hline 7. Seeing the TV & $2,82 \pm 0,59$ & $2,58 \pm 0,51$ & $3,00 \pm 0,0$ & $2,87 \pm 0,67$ & $>0,05$ \\
\hline 8. Seeing moving objects & $3,23 \pm 0,92$ & $2,91 \pm 0,99$ & $3,37 \pm 0,74$ & $3,32 \pm 0,94$ & $>0,05$ \\
\hline $\begin{array}{l}\text { 9. Depth and distance } \\
\text { perception }\end{array}$ & $3,16 \pm 0,92$ & $2,66 \pm 1,07$ & $3,12 \pm 0,64$ & $3,35 \pm 0,87$ & $>0,05$ \\
\hline 10. Seeing see steps and curbs & $3,35 \pm 0,72$ & $3,25 \pm 0,45$ & $3,00 \pm 0,75$ & $3,48 \pm 0,77$ & $>0,05$ \\
\hline 11. Getting around outdoors & $3,27 \pm 0,85$ & $2,83 \pm 1,11$ & $3,12 \pm 0,64$ & $3,48 \pm 0,72$ & $>0,05$ \\
\hline 12. Crossing a street & $3,21 \pm 0,96$ & $2,83 \pm 0,93$ & $3,25 \pm 0,71$ & $3,35 \pm 1,02$ & $>0,05$ \\
\hline \multicolumn{6}{|l|}{ Adaptation to vision loss } \\
\hline 13. Unhappy & $2,51 \pm 1,52$ & $1,58 \pm 0,90$ & $2,63 \pm 1,51$ & $2,84 \pm 1,61$ & $<0,05$ \\
\hline 14. Angry & $4,55 \pm 0,73$ & $4,08 \pm 0,79$ & $4,75 \pm 0,71$ & $4,67 \pm 0,65$ & $<0,05$ \\
\hline 15. Restricted in visits & $3,19 \pm 1,29$ & $3,58 \pm 1,24$ & $3,25 \pm 1,49$ & $3,03 \pm 1,28$ & $>0,05$ \\
\hline 16. Explanation of eye disease & $2,94 \pm 1,97$ & $3,54 \pm 1,81$ & $2,12 \pm 2,29$ & $2,93 \pm 1,93$ & $>0,05$ \\
\hline \multicolumn{6}{|c|}{ Reading and precision requiring activities } \\
\hline 17. Reading large print & $3,25 \pm 1,32$ & $2,50 \pm 1,38$ & $3,25 \pm 0,71$ & $3,55 \pm 1,34$ & $>0,05$ \\
\hline 18. Reading a newspaper & $3,63 \pm 1,18$ & $3,25 \pm 0,86$ & $3,50 \pm 1,07$ & $3,80 \pm 1,30$ & $>0,05$ \\
\hline 19. Reading labels & $3,39 \pm 1,22$ & $2,83 \pm 1,11$ & $3,25 \pm 0,71$ & $3,65 \pm 1,31$ & $>0,05$ \\
\hline 20. Reading letters & $3,68 \pm 1,12$ & $3,50 \pm 0,79$ & $3,75 \pm 0,88$ & $3,74 \pm 1,29$ & $>0,05$ \\
\hline 21. Using tools & $4,68 \pm 0,46$ & $4,41 \pm 0,51$ & $4,63 \pm 0,52$ & $4,81 \pm 0,40$ & $<0,05$ \\
\hline \multicolumn{6}{|l|}{ Everyday activities } \\
\hline 22. Finding out the time & $3,65 \pm 1,14$ & $3,41 \pm 0,79$ & $3,62 \pm 0,92$ & $3,74 \pm 1,32$ & $>0,05$ \\
\hline 23. Writing & $3,71 \pm 1,14$ & $3,50 \pm 0,79$ & $3,75 \pm 0,88$ & $3,77 \pm 1,31$ & $>0,05$ \\
\hline 24. Reading own handwriting & $3,71 \pm 1,12$ & $3,50 \pm 0,79$ & $3,75 \pm 0,88$ & $3,77 \pm 1,28$ & $>0,05$ \\
\hline 25. Everyday activities & $3,63 \pm 1,23$ & $3,50 \pm 0,79$ & $3,63 \pm 0,74$ & $3,67 \pm 1,47$ & $>0,05$ \\
\hline
\end{tabular}

\section{DISCUSSION}

WHO defines the quality of life as "the individual perception of positions of individuals in life within the context of the cultural and value system in which they reside and in relation with their goals, expectations, standards and concerns" The WHOQOL Group 1993 (16).
The QoL is a term which is difficult to be defined due to its multi-factor character. Aaroson NK 1988 (3) determined the QoL as a set of a number of factors: physical health (disease symptoms and treatment), functional (daytime activity, mobility), social (interpersonal contacts and relations) and psychological (mental and emotional balance). 
Table 5. Dependence between QoL and its dimensions and the impairment type (r)

\begin{tabular}{l|c} 
Quality of life & Impairment type \\
General QoL & 0,295 \\
$\begin{array}{l}\text { Distance, mobility and } \\
\text { illumination vision }\end{array}$ & 0,325 \\
Adaptation & 0,147 \\
Reading and fine work & 0,376 \\
$\begin{array}{l}\text { Everyday activities } \\
{ }^{*} \mathrm{p}<0,05\end{array}$ & 0,205 \\
\hline
\end{tabular}

LWQOL was created for patients with impaired vision regardless of their condition. Wolffson J S 2000(18). Glaucoma affects $2 \%$ of the individuals above 40 years of age (14) and the percentage grows dramatically with age. Quigley HA 2006(15)

The data of the questionnaire applied by us show that the individuals with the lowest vision have worst indicators. With age progression the quality of life deteriorates which can be explained with the increasing frequency of the disease. Anhchuong Le et al 2003, Leske M C1995; Dielemans I 1994 C, Mitchell, P 1996 (4,10,7,12).

In spite of the fact that the residence difference is insignificant, the rural population shows the worst

Table 6. Leading causes and quality of life

\begin{tabular}{|c|c|c|c|c|c|}
\hline \multirow[b]{2}{*}{$\begin{array}{l}\text { Leading causes for } \\
\text { blindness and low vision }\end{array}$} & \multicolumn{5}{|c|}{ QUALITY OF LIFE } \\
\hline & $\frac{\overrightarrow{0}}{\stackrel{0}{0}}$ & 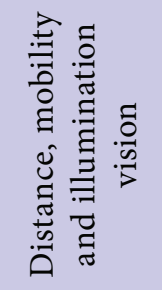 & 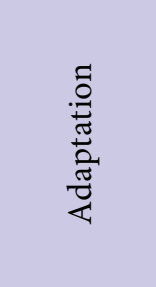 & 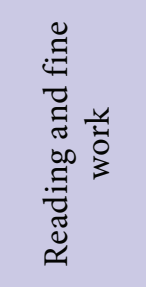 & 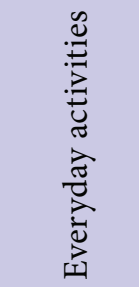 \\
\hline Glaucoma & $81,5 \pm 17,4$ & $37,8 \pm 8,3$ & $12,9 \pm 3,1$ & $18,4 \pm 4,7$ & $14,5 \pm 4,4$ \\
\hline Diabetic retinopathy & $78,7 \pm 20,9$ & $37,2 \pm 10,6$ & $12,2 \pm 3,3$ & $17,4 \pm 5,9$ & $14,2 \pm 4,9$ \\
\hline Cataract & $85,5 \pm 12,7$ & $39,2 \pm 5,9$ & $13,7 \pm 2,9$ & $20,0 \pm 4,4$ & $15,5 \pm 3,7$ \\
\hline Macular degeneration & $80,7 \pm 19,1$ & $37,3 \pm 8,9$ & $13,3 \pm 3,2$ & $18,3 \pm 5,5$ & $14,4 \pm 4,8$ \\
\hline Congenital anomalies & $85,3 \pm 6,1$ & $40,0 \pm 3,0$ & $16,3 \pm 4,1$ & $18,3 \pm 1,5$ & $13,3 \pm 2,3$ \\
\hline Congenital diseases & $82,2 \pm 23,5$ & $40,4 \pm 11,4$ & $12,7 \pm 3,9$ & $18,1 \pm 6,2$ & $14,0 \pm 5,2$ \\
\hline Refractive anomalies & $86,4 \pm 13,6$ & $41,0 \pm 6,1$ & $15,0 \pm 1,7$ & $18,8 \pm 4,5$ & $14,6 \pm 4,9$ \\
\hline Others & $84,3 \pm 18,7$ & $40,1 \pm 9,0$ & $13,6 \pm 2,9$ & $18,9 \pm 5,8$ & $14,3 \pm 5,2$ \\
\hline
\end{tabular}

The health related quality of life should be an important indicator for the provision of health care for patients with chronic diseases for who the complete curing is remote in time and it can be suggested that the treatment will last long, that is why such questionnaires are part of the epidemiologic studies.

Measuring the QoL was at first undertaken to assess the results of cataract surgery Lundstrom M 1997(11). Later the questionnaires for glaucoma Aspinall PA 2008(5), neuritis Cleary PS 1997 (6) were created. The QoL assessment can be done with special questionnaires related to a specific disease or in order to evaluate the effect of a given rehabilitation. quality of life levels. Demographic processes in our country are characterized with decreasing and ageing of population related to the low birth rate, the increase of death rate and the high emigration rates amongst young people. According to data provided by the Ministry of labor and social policy (1), at the end of 2012 the people above 65 years of age are $19.2 \%$ of the population; consequently compared to 2011 the share of the population above 65 years of age has increased with $0.4 \%$, and compared to 2005 it has increased with $2 \%$. The internal migration and territorial re-distribution of the population is an indicator of the different work and life conditions. This led 
to concentration of many people in the district cities and de-population of the villages and ageing of their residents. The average life expectancy for men is 69.90 years and for women is 77.08 years. The relative share of women above 65 years of age is 22.2, and for men it is 16 , due to the higher mortality rate. The ageing process is more significantly expressed in the villages where the average age is 45.5 years, compared to 40.3 years in the cities. In 2010 every fourth village resident will be above 65 years of age (2).

We have found a direct ratio dependency between education and QoL - the low educational degree means low QoL. The higher educational degree is related to a better knowledge and responsibility to the own health and thus education is one of the most important social determinant Uldemolins A R 2012(19). The educational level in the villages is much lower - in $20114 \%$ of the rural population has secondary and high education while in the cities the highly educated people are $71.6 \%$. In the villages 719 127 people have primary education, 655394 people have secondary education and 110613 people have high education. The educational degree is directly depends on the employment and the health culture of the population (2).

The persons that are married have a higher QoL, related to the sense of stability which they receive from their relatives; the widowed persons have a lower QoL as they have to rely on themselves. The lowest QoL is observed for the people living with their children as they perceive this as an additional burden for their relatives, both financial and psychological.

Regarding the employment the retired persons show the worst indicators, due to the low income and the accompanying diseases.

The assessment data for mobility and fine work show bad indicators, a fact that has been stressed out in other studies Aspinall PA 2008, Turano KA 1999 Pradeep Ramulu 2009 (5,17,14). In the meantime only 7,40\% (4 of 54) of the questioned individuals use aiding tools. The probable reason for this is low motivation and lack of information.

The illumination conditions - glare, night vision and getting the right amount of light are also considered. In a study conducted by Lee BL 1998 (9) is noted that $82 \%$ of the persons with glaucoma have difficulties seeing in the dark, compared to a controlled group of patients - $32 \%$.

The QoL of glaucoma patients is significantly decreased Parrish R K 1997, Gutierres P 1997 (13,8). The low vision, the changes in the visual field, combined with the need of treatment determine the low quality of life for patients with this disease. The very setting of such diagnosis is a very stressful fact. The chronic features of this disease, the need of a constant consultations with an ophthalmologist, the functional losses, the incompatibility of using medications and performing one's duties, the side effects of the applied medications and the surgical treatment - both general and local - all these factors influence negatively the QoL.

\section{REFERENCES}

1. Updated national strategy on demographic development of the population of Republic of Bulgaria (2012-2030) Sofia, Ministry of Labor and Social Policy.

2. Health status of city residents in 2009 and implementation of the national health care strategy - annual report of Ministry of Health, Sofia 2010, page 9

3. Aaroson NK Qality of life :what is it ?How should it be measure?1988 Oncoloy (Huntingt) 2,69-76

4. Anhchuong Le, Bickol N M, Catherine A M, Hugh $\mathrm{R} T$. Risk factors associated with the incidence of open-angle glaucoma: The Visual Impairment Project, Ivest Ophthalmol \& Vis Science 2003; 44 (9): 3783-9 doi 10. 1167: ivos.03-0077

5. Aspinall PA, Johnson ZK, Azuara-Blanco A, et al. Evaluation of quality of life and priorities of patients with glaucoma. Invest.Ophthalmol.Vis. Sci 2008;49:1907-1915. Identified the vision-related functions that were most important to subjects with glaucoma

6. Cleary PA,Beck R W,Bourque L B, et al Visual symptoms after optic neuritis: results from the optic neuritis treatment trial J Neuro-Ophthalmol 1997;17:18-28

7. Dielemans I., Vingerling J R, Wolf R C W, et al. The prevalence of primary open angle glaucoma in a population - based study in the Netherlands: The Rotterdam Study Ophthalmology 1994; 101:1851-1855

8. Gutierres P, Wilson R, Johnston C, Gordon M, Cioffi GA, Rich R, Sherwood M, Mong K. 
Mangione C M. Influence of glaucomatous visual field loss on health-related quality of life.Arch Ophthalmol 1997;115(6):777-784

9. Lee BL, Gutierrez P, Gordon M, et al. The Glaucoma Symptom Scale. A brief index of glaucoma-specific symptoms. Arch.Ophthalmol. 1998;116:861-866.

10. Leske M C, Connell, A M, Schachat, A P, Hyman, L. The Barbados Eye Study Prevalence of openangle glaucoma Arch Ophthalmol 1994; 112; 821-9

11. Lundstrom M,Ross P,Jensen S,Fregell G.Catquest questionnaire for use in cataract surgery care:description,validity and reliability.J Cataract Refract Surg 1997;23:1226-1236

12. Mitchell, P., Smith, W., Attebo, K., Healey, P R. Prevalence of open-angle glaucoma in Australia: the Blue Mountains Eye study Ophthalmology 1996; 103:1661-1669

13. Parrish R K,Gedde S j, Scott I U,feuer W J,Schiffman J C,Mangione C M ,MontenegroPiniella A.Visual function and quality of life among patients with glaucoma Arch Ophthalmol 1997;115;1447-55

14. Pradeep Ramulu. Glaucoma and Disability: Which tasks are affected, and at what stage of disease? Curr Opin Ophthalml.2009;20(2):92-98.

15. Quigley HA, Broman AT. The number of people with glaucoma worldwide in 2010 and 2020. Br J Ophthalmol. 2006;90:262-267

16. The WHOQOL Group.Study protocol for the World Health Organization project to develop a Quality of Life assessment instrument (WHOQOL. Qual life Res 1993;2(2):53-159

17. Turano KA, Rubin GS, Quigley HA. Mobility performance in glaucoma. Invest Ophthalmol Vis Sci. 1999;40:2803-2809.

18. Wolffson J S,Cochrane A, Watt N.Implementation methods for vision related of life questionnaires. Br.J .Ophthalmol 2000;84:1035-1040

19. Uldemolins $A$ R,Lansingh van $C$,Valencia $L$ G,Carter M J,Ekckert K.Social inequalities in blindness and visual impairment: A review of social determinants.2012 Sept-Oct;60(5): 368-375 